\title{
Outras Epistemologias para os Estudos de Gênero: feminismos, interseccionalidade e divisão sexual do trabalho em debate a partir da América Latina
}

Recebido: 06-07-2018

Aprovado: 13-12-2018

\author{
Débora Machado ${ }^{1}$ \\ Maria Luisa Walter Costa ${ }^{2}$ \\ Delia Dutra ${ }^{3}$
}

\section{Introdução}

As desigualdades sociais, presentes em todos os países do mundo, ganham especificidades quando analisadas desde uma perspectiva de gênero e interseccional. Mesmo com inegáveis avanços nas últimas décadas, as mulheres continuam a enfrentar múltiplas opressões, que se intensificam conforme sua raça, etnia, origem, sexualidade e classe. Basta ver que o relatório do Fundo de População das Nações Unidas, divulgado em 2017, aponta para o fato de que as mulheres têm mais chance de ficar desempregadas que os homens; ganham 23\% a menos, em média, do que os homens; estão entre a maioria dos analfabetos do mundo; e estão suscetíveis a diversos tipos de violência, tendo em vista que a maior parte dos países analisados sequer tem normativas para tratar do tema (UNFPA, 2017).

Nesse contexto de desigualdades, o pensamento feminista ganha destaque por evidenciar as injustiças sofridas pelas mulheres ao redor do globo e por lhes fornecer elementos que lhes permitam iniciar um caminho de desconstrução de uma lógica masculina dominante. A partir disso, o escopo deste trabalho consiste em elaborar uma

\footnotetext{
${ }^{1}$ Socióloga. Mestranda em Ciências Sociais no PPG-ECsA do Departamento de Estudos LatinoAmericanos da Universidade de Brasília. Pesquisadora do Grupo de Estudos Interdisciplinares sobre Gênero (GREIG/ELA/UnB). Bolsista CAPES. debora.fpm@gmail.com

${ }^{2}$ Cientista Política. Mestranda em Ciências Sociais no PPG-ECsA do Departamento de Estudos LatinoAmericanos da Universidade de Brasília. Pesquisadora do Grupo de Estudos Interdisciplinares sobre Gênero (GREIG/ELA/UnB). Bolsista CAPES. mluizawc@ gmail.com

${ }^{3}$ Doutora em Sociologia. Pesquisadora Colaboradora Plena e Bolsista PNPD/CAPES no Programa de Estudos Comparados sobre as Américas, (ELA, Universidade de Brasília). Coordenadora do Grupo de Estudos Interdisciplinares sobre Gênero (GREIG/ELA/UnB). deliadutra@ gmail.com
} 
discussão teórico-metodológica sobre os feminismos, com foco particular sobre o feminismo decolonial e a perspectiva da interseccionalidade.

Compreendendo que o feminismo decolonial e a interseccionalidade, enquanto paradigma político e teórico, são fundamentais para entender as diversas posições que ocupam as mulheres na sociedade, elencamos a questão da divisão sexual do trabalho para refletir, de forma prática, a articulação de múltiplas diferenças, como raça e classe social, que conectadas entre si produzem desigualdades.

Sem pretensão de esgotar o tema, elaboramos nossas contribuições por meio de revisão bibliográfica, identificando, avaliando e sintetizando evidências relevantes sobre o tema. A atividade consistiu em selecionar informações que forneçam entendimento às perguntas norteadoras do trabalho: quais são as possibilidades e desafios teóricos, metodológicos e práticos do conceito de interseccionalidade? E ainda, quais as implicações desse conceito no marco teórico da divisão sexual do trabalho?

Dessa forma, o presente artigo visa discutir algumas das contribuições epistemológicas do feminismo decolonial para os estudos de gênero, com foco no conceito de interseccionalidade ${ }^{4}$. A primeira parte do artigo tratará do histórico do feminismo como movimento organizado para, em seguida, abordar a crítica ao feminismo tradicional na segunda seção do artigo. O terceiro tópico retoma os trabalhos de María Lugones e Diana Correal de forma a relacionar o feminismo decolonial com o conceito de interseccionalidade; em seguida serão evidenciadas as principais contribuições do conceito da interseccionalidade, discutindo, inclusive, suas implicações no marco teórico da divisão sexual do trabalho. Em uma quarta parte serão expostas algumas das críticas em relação à interseccionalidade, destacando limites na utilização metodológica do conceito; por fim serão apresentadas as considerações finais do trabalho.

\section{Construindo pensamentos e práticas feministas: perspectiva histórica}

$\mathrm{Na}$ leitura de textos feministas, é comum depararmos com menções ao "feminismo de primeira onda", "segunda onda feminista" ou "terceira onda do

\footnotetext{
${ }^{4}$ A seleção de textos utilizadas para tal discussão não tem a pretensão de ser exaustiva ou de esgotar o debate sobre a interseccionalidade. Este artigo explora as potencialidades e os desafios do conceito, e suas implicações no marco teórico da divisão sexual do trabalho.
} 
feminismo". As expressões marcam um momento histórico relevante para o florescimento político e acadêmico de diversas pautas e agendas de mulheres.

Tampouco uma visão em etapas, a expressão “ondas" identifica momentos históricos com demandas de mulheres feministas que viveram em seu tempo, um movimento que "vai e vem"; mesmo que tenha acontecido, suas contribuições permanecem até os dias de hoje.

Assim, o feminismo como movimento organizado surge a partir do final do século XIX e início do século XX, fato que dá início a primeira onda do feminismo ${ }^{5}$.

A primeira onda é caracterizada pela luta pelo direito ao trabalho e direitos políticos, fortemente marcada pelos ideais construídos a partir da Revolução Francesa. A ideia que pautava a luta das mulheres era de indivíduos dotados de direitos (ALONSO; DÍAZ, 2012). No entanto, o movimento foi desenhado sob uma perspectiva específica (ainda que se pretendesse "universal"): a perspectiva das mulheres brancas, burguesas e heterossexuais. A reivindicação ao direito ao trabalho, por exemplo, evidenciava a distância entre mulheres brancas e negras no feminismo liberal.

Enquanto as mulheres brancas reivindicavam sua presença no espaço público, as mulheres negras lutavam pela abolição da escravatura. O papel de Soujourner Truth é emblemático na percepção de que mulheres negras feministas existiam desde a primeira onda, e justamente por serem negras, analisavam sua condição sob o aspecto do racismo. Em 1852, partindo de uma cultura oral própria, Soujourner criticou o processo abolicionista nos Estados Unidos, visto que o movimento feminista branco alcançava o direito ao voto e ao trabalho, enquanto as pessoas negras permaneciam em situação de exclusão (FONSECA, 2016).

Tendo em vista que a retórica do feminismo de primeira onda se iniciou com o intuito de lutar por direitos civis e políticos das mulheres, tem-se um forte cunho liberal em seu surgimento, e é por isso que autoras socialistas, decoloniais e do feminismo negro costumam identificar o feminismo tradicional com o liberalismo e a modernidade (COLLINS, 2002; CORREAL, 2014; FONSECA, 2016; LUGONES 2011; SANTOS; NÓBREGA, 2004).

Afinal, ao apontar que a desigualdade entre homens e mulheres se dá, simplesmente, pela falta da igualdade de direitos, o feminismo tradicional deixa de lado

\footnotetext{
${ }^{5}$ É importante ressaltar, porém, que há um vasto histórico de resistências de mulheres ao longo dos séculos. As resistências, no entanto, não estavam organizadas em grupos.
} 
variáveis fundamentais como classe social, raça, etnia e sexualidade (COLLINS, 2002; CORREAL, 2014; CRENSHAW, 2002; LUGONES 2011; PISCITELLI, 2008).

Questões relacionadas à divisão de classes só viriam com o feminismo socialista, que aponta que a exploração da mulher está intrinsicamente relacionada à exploração econômica. Tal vertente se fortaleceu sobretudo através da segunda onda do feminismo, entre as décadas de 1960 e 1980 (SANTOS; NÓBREGA, 2004).

Também conhecido como feminismo radical, essa "onda" emergiu em meio a um contexto social, político, cultural e econômico em ebulição: guerras e revoluções, rebeliões, etc. A contribuição desta perspectiva consiste na luta e crítica sobre a pobreza e a exploração capitalista que incluem mulheres e homens através das políticas econômicas neoliberais (ALONSO; DÍAZ, 2012).

As feministas de segunda onda, em termos teóricos, questionavam por que as mulheres são oprimidas, e o que todas elas têm em comum que justifique a situação desigual perante aos homens?

Nesse sentido, as feministas de segunda onda apontaram que, apesar da diferença entre todas as mulheres, a opressão com base no sexo é algo que reverbera em todas. Portanto, o feminismo radical se assenta no conceito de patriarcado. Não busca a igualdade com os homens, e sim a abolição da dominação masculina e suas formas de definição, produção e concepção de conhecimento. Além do mais, levanta, de distintas maneiras, o direito a diferença e trouxe para a arena temas como: o corpo, a sexualidade, o direito a decidir sobre a maternidade, identidade sexual (ALONSO; DÍAZ, 2012) ${ }^{6}$.

No entanto, essa corrente tem seus limites no reducionismo da variável econômica, já que outros fatores não são tão relevantes nas análises das feministas socialistas (SANTOS; NÓBREGA, 2004). Nesse sentido, há que se ressaltar outras vertentes, como o feminismo negro nos Estados Unidos a partir da década de 1960, e o feminismo decolonial, estruturado como conceito por autoras latino-americanas, mais

\footnotetext{
${ }^{6}$ A distinção entre sexo e gênero perpassa ao movimento feminista de segunda onda. No âmbito acadêmico, o objeto dos estudos sociais de gênero constitui-se progressivamente no final dos anos 70 e desde lá tem sido produzido uma variedade de investigações com participação de filósofas, cientistas feministas das áreas de natureza, sociais e humanidades. $O$ processo de institucionalização nas universidades foi multivariado (através de ensinos, equipes de pesquisa, redes, coleções de obras, revistas). No livro "Gênero nas Ciências Sociais" relata-se que os estudos de gênero na França inseriramse em programas universitários das Ciências Sociais. O que foi diferente nos países anglófanos, que construiu departamentos interdisciplinares do tipo Women's Studies ou Gender Studies. Ver mais em: CHABAUD-RYCHTER, Danielle; DESCOUTURES, Virginie; DEVREUX, Anne-Marie (Ed.). O gênero nas Ciências Sociais: releituras críticas de Max Weber a Bruno Latour. Editora Unesp, 2014.
} 
recentemente, a partir do século XXI (COLLINS, 2002; CORREAL, 2014; LUGONES 2011). Tais movimentos visam questionar a homogeneização do "ser mulher", inserindo novas categorias, assentadas na transversalidade, para analisar as opressões sofridas.

Esses feminismos, por sua vez, tiveram como fonte o feminismo de terceira onda que entende que as diferenças existentes entre as mulheres (de classe, etnia, raça, sexualidade), apesar das contingências, são constitutivas de suas identidades, experiências de vida e situações de opressão. Assim, a contribuição do feminismo de terceira onda consiste em reconhecer as diferentes identidades e experiências de mulheres. Deste modo, a preocupação com as diferenças intragênero (ou seja, entre as próprias mulheres), problematiza a universalidade do termo "mulher", as concepções e significados fixos e binários.

Valendo-se desse movimento histórico, o feminismo decolonial considera que múltiplas estruturas de opressão operam em articulação à desigualdade de gênero. Desta forma, faz-se necessário, a partir da interseccionalidade, entender como as variáveis de raça, classe, etnia, sexualidade e geopolítica estão inseridas em um sistema em que homens brancos e burgueses estão no comando. Ainda, ressalta-se o questionamento que o feminismo decolonial faz em relação à colonialidade, que inferioriza as mulheres negras e indígenas.

A perspectiva histórica descrita, contudo, está localizada em categorias feministas desenvolvidas nos contextos sociais e políticos estadunidense e europeus. Nesse sentido, essas categorias, de fato, nos permitem pensar a situação de opressão das diferentes mulheres negras, indígenas, migrantes, racializadas da América Latina?

\section{Construindo Feminismos: crítica decolonial ao feminismo tradicional}

Sob diferentes perspectivas teóricas, feministas têm apontado a exclusão histórica, teórica e prática das mulheres não brancas nas lutas empenhadas pelas mulheres. As teóricas decolonais, como é o foco deste trabalho, balizam que o sujeito encarnado pelo feminismo tradicional não é qualquer sujeito, e sim a mulher branca, que, a despeito das opressões que sofre, também se beneficia de um mundo operado pela lógica colonial e racial.

O feminismo decolonial é um projeto político e teórico que desafia as práticas imperialistas e colonizadoras do passado e do presente (MENDONZA, 2015). No bojo de suas formulações, faz-se necessário compreender que o giro decolonial 
contemporâneo no mundo acadêmico foi liderada por estudiosos latino-americanos e caribenhos associados ao Grupo Modernidade/Colonialidade que ofereceram uma reinterpretação das relações capitalistas ao afirmar que a raça é central nessa estrutura de acumulação. De forma geral, o grupo argumenta que a modernidade e o capitalismo são resultados históricos do colonialismo.

Ou seja, apesar da independência dos poderes coloniais na América Latina e Caribe, as instituições políticas, a racionalidade científica, a estrutura de pensamento, e as hierarquias raciais e étnicas e de gênero do período colonial permanecem, reatualizadas, até os dias de hoje. Por isso, a modernidade deve ser analisada dialeticamente com a colonialidade.

O eixo do grupo pode ser definido por "uma reflexão continuada sobre a realidade cultural e política latino-americana, incluindo o conhecimento subalternizado dos grupos explorados e oprimidos" (ESCOBAR, 2003, p.53).

O giro decolonial é a marca política, epistêmica e teórica desse programa de investigação que oferece contribuição na compreensão das lógicas de dominação e colonização da América Latina em diversas esferas: nas relações geopolíticas, de raça, gênero, sexualidade. Ao mesmo tempo, se propõe a traçar estratégias de pensamento (não hierárquicas e não binárias) que superem a colonialidade das relações de poder estabelecidas. Como explica Castro-Gómez e Grosfoguel:

\footnotetext{
O conceito de 'decolonialidade' [...] resulta útil para transcender a suposição de certos discursos acadêmicos e políticos, segundo o qual, com o fim das administrações coloniais e a formação dos Estados-nação na periferia, vivemos agora em um mundo descolonizado e pós-colonial. Nós partimos, ao contrário, do pressuposto de que a divisão internacional do trabalho entre centros e periferias, assim como a hierarquização étnico-racial das populações, formada durante vários séculos de expansão colonial europeia, não se transformou significativamente com o fim do colonialismo e a formação dos Estados-nação na periferia (CASTRO-GÓMEZ; GROSFOGUEL, 2007, p. 13)
}

Sob essa perspectiva, a colonialidade consiste na negação da existência de outros mundos e cosmovisões. A colonialidade é constitutiva da modernidade, pois ela só se tornou possível através das lógicas de dominação, opressão e exclusão do "outro" fundadas pelo poder colonial. Com o objetivo de analisar as dimensões culturais, econômicas, políticas e sociais da lógica moderna/colonial, o conceito de colonialidade do poder é central.

Colonialidade do poder é um conceito que dá conta de um dos elementos fundantes do atual padrão de poder, a classificação social básica e universal da população do planeta em torno da ideia de "raça". Essa ideia e a classificação social e baseada nela (ou 
"racista") foram originadas há 500 anos junto com América, Europa e o capitalismo. São a mais profunda e perdurável expressão da dominação colonial e foram impostas sobre toda a população do planeta no curso da expansão do colonialismo europeu. Desde então, no atual padrão mundial de poder, impregnam todas e cada uma das áreas de existência social e constituem a mais profunda e eficaz forma de dominação social, material e intersubjetiva, e são, por isso mesmo, a base intersubjetiva mais universal de dominação política dentro do atual padrão de poder. (QUIJANO, 2002, p4)

Contudo, a análise de gênero ocupa um espaço liminar na teoria decolonial. Maria Lugones, por exemplo, expõe que a concepção de gênero dos teóricos decoloniais está presa no determinismo biológico, pressupondo um dimorfismo sexual. A autora crítica Quijano por naturalizar a heteronormatividade e por conservar uma visão eurocêntrica sobre os gêneros, pois como argumenta Lugones, "o gênero não existia como princípio organizador do poder nas sociedades indígenas antes do processo de colonização" (MENDONZA apud LUGONES, 2015, p.19 - tradução nossa)

As apreciações, por sua vez, iluminam o fato de que o feminismo decolonial propõe uma revisão crítica das estruturas de dominação do conhecimento e do poder. No entanto, trata-se de um espaço aberto, de diálogo e revisão contínua. Reúne pessoas e epistemologias que não necessariamente se intitulam feministas ou decolonais, mas que estão em questionamento e oposição a uma razão imperial racista (ESPINOSA, 2014).

O feminismo decolonial advém de várias tradições: não só do saber acadêmico reconhecido, o pensamento social latino-americano, como também se nutre dos conhecimentos populares e comunitários para elaborar um saber crítico e traçar estratégias para a emancipação das mulheres, sexualidades e gêneros.

A partir das contribuições do grupo modernidade/colonialidade este feminismo se apoia na ideia de interseccionalidade para enfocar como as questões de poder e dominação (raça, gênero, classe e sexualidade) se implicam mutuamente e operam de maneira estrutural. Trata-se, portanto, das implicações entre colonialidade de poder e gênero (LUGONES, 2011), que permitem revisar as teorias do feminismo ocidental universalista, a ideia de um patriarcado universal, assim como explicar como a colonização introduziu o sistema de gênero capitalista eurocentrado colonial.

Em função desse contexto, é relevante discutir as contribuições epistemológicas de Maria Lugones e Diana Correal para os estudos de gênero com foco no conceito de interseccionalidade, dada a centralidade dessa noção no pensamento das feministas decolonais. 


\section{Feminismo Decolonial e Interseccionalidade: um debate a partir de María Lugones e Diana Correal}

Duas autoras que trabalham o feminismo decolonial são María Lugones, pensadora argentina, e Diana Correal, colombiana. Alguns pontos convergem entre os trabalhos das autoras, como a necessidade de questionar os universalismos inerentes ao feminismo tradicional, e a importância da interseccionalidade para bem compreender as diferentes posições que as mulheres ocupam na sociedade.

Segundo Correal, foi a partir do discurso moderno ilustrado que o feminismo pode alçar-se politicamente, ainda que várias histórias de resistência de mulheres possam ser evocadas em distintos momentos. A modernidade Ilustrada considera o sujeito como universal e defende que a sociedade moderna ocidental é o modelo a ser seguido para se chegar ao progresso (CORREAL, 2014).

Na modernidade ilustrada, universalidade e igualdade são conceitos que formam um modelo único de sociedade. Esse pensamento justifica a ideia de que o progresso é linear e racional (CORREAL, 2014). Assim, foi a partir da bandeira da "igualdade", que as mulheres do Norte global reivindicaram seus direitos frente à sobreposição social dos homens. Nesse sentido, o feminismo tradicional nasce a partir da realidade dessas mulheres, especificamente.

É importante dizer que a universalidade do sujeito moderno era pensada a partir de um tipo de vivência: a dos homens brancos, burgueses e heterossexuais. Um dos preceitos fundamentais para entender a modernidade é a sua lógica categorial e dicotômica (LUGONES, 2011). Assim, a modernidade foi pensada hierarquicamente, conforme as características do sujeito (que de universal, nada tinha). Esse sistema hierárquico era organizado, em primeiro lugar, pela divisão racial: os brancos, tanto homens quanto mulheres, estavam acima de negros e indígenas. Ademais, a hierarquia seguia com divisões de classe, de sexo e de origem nacional.

Em contraposição a esse pensamento, surge o projeto decolonial ${ }^{7}$, que considera várias subjetividades e busca romper epistemologicamente com o projeto moderno

\footnotetext{
${ }^{7}$ Nesse âmbito, é importante ressaltar o conceito de colonialidade do poder, cunhado por Quijano em 1989. A contribuição do termo está em reconhecer que a relações coloniais de dependência e subordinação estão presentes mesmo com o fim do colonialismo formal. Além disso, pode-se falar em colonialidade em diferentes dimensões, como a do poder, do saber e do ser, discutidas por Mignolo e Maldonado-Torres (MALDONADO-TORRES apud BALLESTRIN, 2013, p. 100). Acrescenta-se, ainda, a colonialidade de gênero, ou seja, a existência de um sistema moderno/colonial eurocêntrico de gênero
} 
colonial. Mesmo que marcado por diversidades quanto à agenda, tal projeto objetiva, por exemplo, reconhecer novas formas de organizar a economia e de se relacionar com a natureza, considerando a interculturalidade e a espiritualidade. Ainda dentro do projeto decolonial pode-se considerar o feminismo decolonial, já que este também critica construções universais baseadas na visão de mundo ocidental (CORREAL, 2014).

Correal (2014) argumenta que o feminismo focou na discussão sobre o patriarcado e deixou de lado dimensões importantes como a colonialidade e a hegemonia da perspectiva da mulher branca. Ademais, a autora alerta para o fato de que o feminismo muitas vezes reproduziu o projeto totalizador da modernidade. Correal conclui que a América Latina apresenta enorme diversidade e visões alternativas de mundo, e que isso pode se contrapor ao projeto de modernidade hegemônico. Assim, é fundamental que o feminismo parta dessa perspectiva.

Tanto o patriarcado quanto a modernidade/colonialidade devem ser discutidos na agenda do feminismo decolonial. O patriarcado não deve ser considerado universalmente, segundo Lugones. Além disso, não há que se falar em mulher como sujeito universal. Há diferenças de raça, gênero, classe e sexualidade que devem ser levadas em consideração. Correal escreve que: "o feminismo se focalizou em contestar a ideia da mulher como frágil, débil de corpo e mente, restrita à esfera privada e sexualmente passiva, sem discutir que essas eram características das [...] brancas burguesas" (2014, p. 257, tradução nossa).

Outro exemplo da dicotomização do mundo feita pelo projeto moderno, assentada no cristianismo e em seu maniqueísmo, foi pensar a mulher europeia como casta, pura e cristã; e a mulher negra e indígena como selvagem, impura, e com a sexualidade latente (LUGONES, 2011).

Há que se considerar, porém, que o "ser mulher" tem muitos significados e representações, além de que as mulheres possuem cosmovisões específicas conforme o contexto em que estão inseridas. Daí deriva a importância do conceito de interseccionalidade para as análises que discutam feminismos ${ }^{8}$ e gênero. Em se tratando das mulheres latino-americanas, faz-se necessário compreender que a posição das

que ignora categorias de raça, classe, sexualidade em sua constituição (LUGONES, 2011). O projeto descolonial se insere justamente na tentativa de ruptura desses sistemas de opressão.

${ }^{8}$ Aqui, pela primeira vez, falamos em feminismos no plural. Afinal, é preciso combater o universalismo inerente ao feminismo tradicional hegemônico, e considerar as manifestações feministas, que lutam pela igualdade de gênero, nas suas mais diversas particularidades. 
mulheres negras e indígenas é muito distinta daquela ocupada pelas mulheres brancas, com descendência europeia.

Inclusive, um dos questionamentos de vários movimentos de mulheres é se a bandeira do feminismo deve ser erguida por mulheres subalternizadas e invisibilizadas pelo próprio feminismo tradicional. Alguns movimentos de mulheres preferem não se identificar com o feminismo justamente por seu contexto de surgimento que desconsidera a realidade de outras mulheres que não as europeias e norte-americanas. No entanto, na visão de Lugones (2011), o feminismo, além de nos mostrar a opressão, é uma forma de nos ensinar como não sucumbir a ela. Assim, a autora prefere continuar a utilizar o termo feminismo, porém reformulado a partir da perspectiva das mulheres latino-americanas.

Defensora do feminismo decolonial, Lugones escreve que "se mulher e negro são termos para categorias homogêneas, atômicas, separáveis, então sua intercessão nos mostra a ausência das mulheres negras em vez de sua presença" (LUGONES, 2011, p. 106, tradução nossa). Assim, ao ter em mente a interseccionalidade, é possível questionar a lógica categorial moderna estanque, que classifica o indivíduo em vários grupos definidos, permitindo, assim, dar mais fluidez às análises de gênero.

\section{Interseccionalidade: suas origens e principais contribuições}

A perspectiva da interseccionalidade surge por volta da década de 1980 influenciada pelos escritos críticos que questionavam os pressupostos do pensamento feminista tradicional, como a distinção entre sexo e gênero. A divisão sexo/gênero formulava a existência de uma base biológica, e, com efeito, a humanidade se separava de forma fixa entre dois sexos e dois gêneros diferentes entre si, atribuindo universalidade a essa distinção.

Nos estudos críticos a noção corrente do pensamento feminista sobre o patriarcado é problematizada, particularmente o caráter transhistórico deste conceito 9 . Desta forma, questiona-se a universalização das relações de dominação masculina, das relações de poder presentes no paradigma ocidental das relações de gênero.

\footnotetext{
${ }^{9}$ Sobre a noção de patriarcado, vale destacar que há diferentes formas de concebê-lo. De acordo com o feminismo radical, o patriarcado é um sistema de opressão que implica na realidade separada entre mulheres e homens. A perspectiva socialista, por sua vez, pensa o patriarcado como uma dimensão histórica, que varia ao longo do tempo, e relacionada a uma base material, ou seja, aos modos de produção e reprodução do capitalismo (ALONSO\&DÍAZ, 2012; PISCITELLI, 2008).
} 
Aproximando-se das abordagens desconstrutivistas, as autoras do pensamento crítico feminista passaram a trabalhar com a noção pulverizada de poder, valorizando a linguagem e o discurso como práticas relacionais, e compreendendo a produção de conhecimento como um ato de poder (PISCITELLI, 2008).

Diante deste contexto, a interseccionalidade surge como uma proposta teóricometodológica para compreender as relações sociais de poder e os contextos em que se produzem as desigualdades sociais entre mulheres e homens, considerando as diferentes classificações sociais historicamente situadas (CRENSHAW, 2002; PISCITELLI, 2008; MAGLIANO, 2015).

As preocupações em torno da interseccionalidade foram iniciadas pelo movimento de feministas negras nos Estados Unidos. No esforço de desconstrução das categorias "mulheres" e "negras" emergiu-se a necessidade de refletir sobre os processos de produção e reprodução de desigualdades sociais, sendo as mulheres de cor o objeto de estudo daquele grupo ${ }^{10}$.

Influenciada por este contexto, Kimberlé Crenshaw (2002) cunhou o conceito de interseccionalidade ${ }^{11}$ com o intuito de problematizar a concepção de gênero como uma dimensão entre outras no complexo de relações sociais e políticas - embora as mulheres estejam sujeitas a discriminação de gênero, também é verdade que outros fatores associados a identidades sociais (como raça, classe, etnia, religião, idade) são diferenças que fazem a diferença na forma pela qual vários grupos de mulheres vivenciam a discriminação.

As interseccionalidades são formas de capturar as consequências da interação entre duas ou mais formas de subordinação que criam desigualdades básicas e estruturam as posições relativas de mulheres, raças, etnias, classes e outras ${ }^{12}$.

\footnotetext{
${ }^{10}$ O trabalho pioneiro de Patricia Hill Collins (2002), por exemplo, se concentra nas dimensões entre gênero e raça para pensar as múltiplas desigualdades e formas de opressão que enfrentam as mulheres negras nos Estados Unidos. Sua contribuição consiste em encarar a raça, a etnicidade e o gênero como dimensões socialmente construídas e organizadoras do sistema social.

${ }^{11}$ A reflexão sobre interseccionalidade pode ser remetida a um histórico anterior, sendo iniciada por Sojourner Truth em seu discurso na Convenção dos Direitos das Mulheres em Akron em 1852. Partindo de uma cultura oral própria, Sojourner Truth criticou o processo abolicionista nos Estados Unidos, visto que o movimento feminista branco alcançava o direito ao voto, enquanto as pessoas negras permaneciam em situação de exclusão (FONSECA, 2016).

${ }^{12}$ Ressalta-se que o conceito foi sendo construído com uso de diferentes termos ao longo do tempo ("simultaneidade", "matriz de dominação", "categorias de articulação", entre outras), representando, assim, a coexistência de distintas leituras e abordagens (PISCITELLI, 2008; MAGLIANO, 2015), e a influência da literatura pós-modernista e dos movimentos de mulheres indígenas e chicanas (ALONSO; DÍAZ, 2012).
} 
Utilizando uma metáfora de intersecção, [...] os vários eixos de poder, isto é, raça, etnia, gênero e classe constituem as avenidas que estruturam os terrenos sociais, econômicos e políticos. É através delas que as dinâmicas do desempoderamento se movem. Essas vias são por vezes definidas como eixos de poder distintos e mutuamente excludentes; o racismo, por exemplo, é distinto do patriarcalismo, que por sua vez é diferente da opressão de classe. $\mathrm{Na}$ verdade, tais sistemas, frequentemente, se sobrepõem e se cruzam, criando intersecções complexas nas quais dois, três ou quatro eixos se entrecruzam (CRENSHAW, 2002, p.177)

A proposta da noção de interseccionalidade é oferecer ferramentas analíticas para compreender a articulação entre múltiplas diferenças e desigualdades. As contribuições desta elaboração teórica podem ser sintetizadas em três aspectos fundamentais (MAGLIANO, 2015, p.695).

O primeiro deles é que a interseccionalidade desafia o modelo hegemônico de mulher universal. Em segundo lugar, considera-se que gênero, etnicidade, raça, classe, entre outras classificações, operam em múltiplos níveis da vida social. Desta forma, a interseccionalidade trata não só de identidades individuais, como também das relações materiais de desigualdade.

Por fim, reflete que a produção de conhecimento deve considerar as posições e classificações sociais de maneira relacional, o que implica em um esforço de não reduzir as experiências dos sujeitos de investigação em uma só categoria. Essa potencialidade se expressa nas investigações que relacionam a questão da divisão sexual do trabalho com categorias de articulação como gênero, raça e classe social.

\section{Interseccionalidade e seus Desafios Metodológicos}

A centralidade que tem adquirido a perspectiva teórica da interseccionalidade vem acompanhada de uma série de questionamentos sobre como operacionalizar, metodologicamente, as argumentações propostas pelo conceito. Dificuldade esta que surge no momento de analisar empiricamente as formas em que a simultaneidade de classificações sociais opera em determinados grupos sociais. Diante desta problemática, uma crítica à interseccionalidade é a carência de discussões sobre como aplicá-la na práxis.

Em particular, critica-se a distância entre estratégias metodológicas e as práticas de investigação sustentadas por essa perspectiva: embora a perspectiva interseccional afirme que uma pessoa não enfrenta lógicas de exclusão de forma aditiva, e sim pela interseção de diversos eixos de subordinação, "metodologicamente as pesquisas 
continuam replicando a mesma abordagem que criticam” (MAGLIANO, 2015, p.697, tradução nossa).

Diante dos desafios de utilização do conceito, é importante destacar o risco de assumir como dadas as categorias de classificação social que identificam as lógicas de opressão e desigualdade. Como comenta Crenshaw (2002), por exemplo, raça e etnia podem não ser marcadores constantes em todo o mundo. Nesse sentido, ao invés de abordagens homogêneas, torna-se necessário realizar análises contextuais, pois as categorias de análise interseccionais têm contexto histórico específico, ou seja, não existe uma única forma de interseccionalidade, e sim várias, a depender do grupo e seu contexto social, cultural e político (CRENSHAW, 2002; MAGLIANO, 2015). As categorias interseccionais, portanto, devem ser pensadas como processos fluidos e dinâmicos.

Contudo, surge a pergunta: qual é o objeto de análise desta perspectiva teórica? Conforme ressalta Magliano (2015), existem dois posicionamentos relevantes sobre esta questão. O mais significativo deles advoga pelo foco nas posições particulares daqueles que cotidianamente enfrentam a opressão e a exclusão. $O$ objeto de análise, segundo esta corrente de abordagem, é a pessoa ou o grupo oprimido, sob o qual recaem lógicas de dominação e desigualdade.

A segunda corrente, por sua vez, considera que a interseccionalidade faz referência a todas as posições do sujeito, as quais são fundamentalmente construídas pelo gênero, raça, classe, sexualidade, entre outras. No entanto, ambas as abordagens provocam dúvida sobre o aparente número ilimitado de categorias interseccionais a serem analisadas em termos teóricos e metodológicos. Sobre este aspecto, as pesquisadoras e pesquisadores devem se atentar para o fato de que existem situações históricas específicas que influenciam a relevância de determinadas classificações em relação a outras na estrutura social. E, para perceber esses contextos, é preciso se colocar em posição de abertura em relação ao campo que se estuda.

Outro ponto em discussão sobre a perspectiva da interseccionalidade é a tensão entre as identidades sociais e a estrutura social que emerge da interseccionalidade. A leitura recorrente sobre interseccionalidade (CRENSHAW, 2002) destaca o impacto da estrutura social, pois as categorias gênero, raça e classe são pensadas como sistemas de dominação e opressão que necessariamente determinam identidades. Contudo, os marcadores sociais da diferença determinam por si só a desigualdade? 
Alinhadas a uma leitura sistêmica, algumas pesquisadoras resolvem essa questão afirmando que qualquer análise sobre a desigualdade social deve considerar os indivíduos e as estruturas, pois estas não estão desprovidas de classificações sociais. As leis, a política, a religião, o Estado-nação, e o mercado de trabalho, por exemplo, são constituídos pelo gênero, raça, etnia, classe social, etc. Assim, sob esta perspectiva, há uma certa complementariedade entre identidade e estrutura (MAGLIANO, 2015).

Por outro lado, há uma leitura construcionista que não enxerga os marcadores sociais como formas limitantes de classificação. As categorias gênero, raça, classe em sua simultaneidade podem oferecer recursos que possibilitam a ação, pois a diferença nem sempre é marcadora de hierarquia e opressão. Portanto, questiona-se o fato de as categorias gênero, raça e classe serem pensadas como sistemas de dominação e opressão que necessariamente determinam identidades (PISCITELLI, 2008).

O profícuo debate sobre as noções de diferença e desigualdade também está relacionado à interpretação dada a ideia de "poder" que, de modo geral, tem Foucault como referência. Conforme apresentado por Piscitelli (2008), o enfoque sistêmico da interseccionalidade deixa de lado a dimensão produtiva do poder: ele não só reprime como também produz sujeitos. Além do mais, é preciso considerar que as relações de poder se alteram constantemente e são marcadas por conflitos e resistências.

Por isso, a crítica desta vertente é de que, na abordagem sistêmica, a interseccionalidade está "voltada a revelar o poder unilateral das representações sociais e as consequências materiais e simbólicas para os grupos atingidos pelos sistemas de subordinação" (PISCITELLI, 2008, p.268). Ou seja, os sujeitos são constituídos por sistemas de dominação carentes de agência.

Os desafios que apresenta a perspectiva da interseccionalidade, contudo, não invalidam suas contribuições. Como argumenta Magliano (2015), esses "problemas" são como caminhos abertos que se traduzem em desafios às pesquisadoras e pesquisadores, uma vez que nos levam a refletir sobre os traçados teóricos e metodológicos possíveis para compreender as variadas experiências de desigualdade e resistência dos mais diversos grupos sociais.

\section{Colocando em prática: análise interseccional sobre a divisão sexual do trabalho na América Latina}

O conceito "divisão sexual do trabalho" foi criado há cerca de 40 anos, na França, ainda que já houvesse alguns trabalhos esparsos anteriores que versassem sobre 
o tema. Inicialmente, o conceito nasceu de um questionamento acerca do trabalho doméstico, que era invisibilizado, e não era considerado propriamente como trabalho. Ainda, cabia às mulheres executá-lo por uma questão de dever moral. Com o tempo, o trabalho doméstico passou a ser considerado como trabalho profissional por essa literatura (HIRATA; KERGOAT, 2007).

Hirata e Kergoat defendem que a divisão sexual do trabalho está intimamente ligada às relações sociais entre os sexos. Nesse sentido, esse sistema "tem como característica a designação prioritária dos homens à esfera produtiva e das mulheres à esfera reprodutiva e, simultaneamente, a apropriação pelos homens das funções com maior valor social adicionado (políticos, religiosos, militares etc)" (HIRATA; KERGOAT, 2007, p. 599).

Apesar de o conceito surgir em um contexto europeu, foi disseminado para várias áreas, e utilizado, também, para entender realidades além da Europa. Na América Latina, $90 \%$ do trabalho doméstico é feito por mulheres, além de que, das mulheres ocupadas, $15 \%$ exercem trabalho doméstico (OIT, 2013). A região tem a maior taxa de trabalho doméstico do mundo, o que revela a importância de se discutir o tema.

Além disso, é fundamental considerar que a divisão sexual de trabalho é também racial. No Brasil, por exemplo, “entre 2004 e 2011, a proporção de mulheres negras ocupadas nos serviços domésticos no país cresceu de $56,9 \%$ para $61,0 \%$, ao passo que entre as mulheres não negras observou-se uma redução de $4,1 \%$ pontos percentuais, com a participação correspondendo a 39,0\%, em 2011” (DIEESE, 2013, p. 6). Quando se observa o Distrito Federal, Unidade Federativa que abriga a capital do país, observase que $80 \%$ dos trabalhadores domésticos da região de 2006 a 2016 era de mulheres negras (BRASIL, 2016).

Nesse sentido, a divisão sexual de trabalho deve ser analisada, também, a partir de uma lógica transversal e interseccional. Não é possível fazer análises de gênero sob esse prisma que desconsiderem as variáveis de raça e classe. Afinal, mesmo que a divisão sexual do trabalho incida sobre as mulheres brancas - através, por exemplo, dos trabalhos relativos ao cuidado com os filhos e pessoas idosas da família - há que se considerar que estas têm o acesso ao mercado de trabalho qualificado facilitado pelo trabalho doméstico remunerado exercido pelas mulheres negras e indígenas.

Em conclusão, é essa, fundamentalmente, a contribuição teórica e epistemológica que o feminismo decolonial - que busca romper com o universalismo centrado em apenas um modelo de sujeito - e a interseccionalidade - que dá mais fluidez 
às categorias dicotômicas modernas - têm a dar para análises que discutem divisão sexual do trabalho.

\section{Considerações finais}

Embora os posicionamentos feministas possam ser muito distintos, há pontos em consenso. O primeiro deles é que o gênero, em interação com outras categorias como raça, etnia, idade, sexualidade, é um organizador da vida social. O segundo aspecto em concordância é a necessidade de mudança dessas estruturas sociais que produzem e reproduzem desigualdades, principalmente na luta pelos direitos humanos das mulheres e demais grupos historicamente marginalizados dos processos de tomada de decisão e produção do conhecimento.

Desta maneira, ao utilizar as lentes de gênero para ler o mundo, nos deparamos com diversas interpretações e teorias. Ou seja, não existe um pensamento único feminista. Contudo, foi construído socialmente um pensamento feminista hegemônico que tem como característica a perspectiva branca, burguesa e eurocentrada. Em relação à perspectiva tradicional hegemônica, o feminismo decolonial evidencia a histórica exclusão das mulheres não-brancas nas lutas pela liberdade e igualdade da "mulher". A mulher, neste caso, pensada como sujeita universal.

Sobre este aspecto, cabe destacar a experiência da América Latina e Caribe, pois as marcas do colonialismo abrem possibilidades de crítica ao feminismo branco, heterossexual e etnocêntrico. Nesse sentido, o conceito de interseccionalidade propõe para as ciências sociais e humanas uma análise sobre as diferentes formas de opressão e das formas em que a "ferida colonial" se encarna nos corpos situados historicamente em processos particulares e locais.

Portanto, o movimento epistemológico tem sido de abandono da investigação de um só ponto de vista e vai em uma direção mais plural. Ancorado na ideia de interseccionalidade, o pensamento feminista decolonial, aqui discutido através das contribuições de Lugones (2011) e Correal (2014), tem revisado as teorias do feminismo ocidental universalista.

Ademais, as autoras argumentam que colonização introduziu o sistema de gênero capitalista eurocentrado colonial. Desta forma, as categorias gênero e raça separados não conseguem explicar a violência contra mulheres negras, tampouco as opressões sofridas por mulheres camponesas e indígenas no contexto do capitalismo global, pois o 
capitalismo não é apenas um sistema de exploração de classe. Ele surge simultaneamente como um sistema marcado pelo gênero e pela raça (LUGONES, 2011). Questões que se articulam com o tema do trabalho doméstico e a divisão sexual do trabalho.

Neste artigo argumentamos que a divisão sexual de trabalho deve ser analisada a partir de uma lógica transversal e interseccional. Não é possível fazer análises de gênero sob esse prisma que desconsiderem as variáveis de raça e classe. No entanto, é importante observar as potencialidades e os limites teórico-metodológicos da interseccionalidade. Esta nos abre a possibilidade de elaborar categorias analíticas num diálogo permanente entre o teórico e o empírico, justamente para evitar a interpretação da realidade tomando de antemão teorias e categorias previamente homologadas pelo saber científico.

Por esse motivo, é preciso deixar-se surpreender com a realidade e ampliar o olhar interpretativo, levando em consideração a perspectiva interseccionada de opressões e resistências que variam de acordo com o grupo, contexto social, cultural e político.

\section{Referências}

ALONSO, Graciela; DÍAZ, Raúl.. Reflexiones acerca de los aportes de las epistemologias feministas y decoloniales para pensar la investigacíon social. Debates Urgentes-Dossier: Pensamiento crítico y cambio, v. 1, n. 1, pp. 75-97, 2012.

BALLESTRIN, Luciana.. América Latina e o giro decolonial. Revista Brasileira de Ciência Política, n. 11, pp.89-117, 2013.

BARROSO, J. M.. Feminismo decolonial: una ruptura con la visión hegemónica eurocéntrica, racista y burguesa. Entrevista con Yuderkys Espinosa Miñoso. Iberoamérica Social: revista-red de estudios sociales (III), pp. 22 - 33, 2014. Disponível em: http://iberoamericasocial.com/feminismo-decolonial-una-ruptura-con-la-visionhegemonica-eurocentrica-racista-yburguesa.

BLAZQUEZ-GRAF, Norma.. Epistemología feminista: temas centrales, en: Blázquez, N., Flores, F., \& Ríos, M. (coord.), Investigación feminista: epistemología, metodología y representaciones sociales. México, UNAM pp. 21-38, 2012.

BRASIL.. Companhia de Planejamento do Distrito Federal (CODEPLAN), PED Pesquisa de Emprego e Desemprego, 2016. Disponível em: $\mathrm{http}: / / \mathrm{www} . c o d e p l a n . d f . g o v . b r / c o m p o n e n t / c o n t e n t / a r t i c l e / 261$-pesquisassocioeconomicas/258-ped.html. Acesso em nov. de 2017. 
CASTRO-GÓMEZ, Santiago; GROSFOGUEL, Rámon. (Eds.). El giro decolonial: reflexiones para una diversidad epistémica más allá del capitalismo global. Bogotá: Siglo del Hombre Editores, 2007.

COLLINS, Patricia Hill.. Black feminist thought: Knowledge, consciousness, and the politics of empowerment. Routledge, New York, pp.251-271, 2002.

CORREAL, Diana Marcela Gómez.. Feminismo y modernidad/colonialidad: entre retos de mundos posibles y otras palabras, en: Y. E. Miñoso, D. G. Correal, K. O. Muñoz (eds.), Tejiendo de otro modo: Feminismo, epistemología y apuestas descoloniales en Abya Yala. Colombia, Universidad de Cauca, pp 353-369, 2014.

CRENSHAW, Kimberlé.. Documento para o encontro de especialistas em aspectos da discriminação racial relativos ao gênero. Revista Estudos Feministas, v.10, n.1, 2002, pp. 171-189.

DIEESE, Departamento Intersindical de Estatística e Estudos Socioeconômicos.. O emprego doméstico no Brasil. Estudos e pesquisas, n. 68, 2013, pp. 1-27. Disponível em: https://www.dieese.org.br/estudosetorial/2013/estPesq68empregoDomestico.pdf. Acesso em nov. 2017.

ESCOBAR, Arturo.. "Mundos y conocimientos de otro modo: el programa de investigación modernidad/colonialidad latino-americano". Tábula Rasa, n.1, 2003, p. 58-86. Disponível em: http://www.redalyc.org/articulo.oa?id=39600104>

FONSECA, Lívia Gimenes Dias da.. Despatriarcalizar e decolonizar o estado brasileiro: um olhar pelas políticas públicas para mulheres indígenas. Tese (Doutorado em Direito), Universidade de Brasília, Brasília, 2016.

G1 Mundo.. Situação de desigualdade das mulheres ameaça desenvolvimento mundial, conclui relatório da ONU, $2017 . \quad$ Disponível em: https://g1.globo.com/mundo/noticia/situacao-de-desigualdade-das-mulheres-ameacadesenvolvimento-mundial-conclui-relatorio-da-onu.ghtml. Acesso em nov. de 2017.

HARDING, Sandra.. "Rethinking Standpoint Epistemology: What is 'strong objectivity'?", in S. Harding (ed.), The Feminist Standpoint Theory Reader. Intellectual and Political Controversies. Routledge, New York, 2004, pp. 127-140.

HIRATA, Helena; KERGOART, Danièle.. Novas configurações da divisão sexual do trabalho. Cadernos de Pesquisa, v. 37, n.132, 2007, pp. 595-609.

LUGONES, María.. Hacia un feminismo descolonial. La manzana de la discórdia, v.6, n.2, 2011, pp.105-119.

MAGLIANO, María José.. Interseccionalidad y migraciones: potencialidades y desafíos. Revista Estudos Feministas, v.23, n.3, 2015, pp.691-712.

MENDONZA, Breny. Coloniality of Gender and Power: From Postcoloniality to Decoloniality. Oxford Handbooks Online, 2015. Disponível em: http://www.oxfordhandbooks.com/view/10.1093/oxfordhb/9780199328581.001.0001/o xfordhb-9780199328581-e-6 
OIT, Organização Internacional do Trabalho. Quase 20 milhões de pessoas realizam trabalho doméstico remunerado na América Latina, 2013. Disponível em: http://www.oitbrasil.org.br/content/quase-20-milhoes-de-pessoas-realizam-trabalhodomestico-remunerado-na-america-latina. Acesso em dez. de 2017.

PISCITELLI, Adriana.. Interseccionalidades, categorias de articulação e experiências de migrantes brasileiras. Sociedade e cultura, v. 11, n. 2, 2008, pp.263-274.

QUIJANO, Aníbal.. "Colonialidade, Poder, Globalização e Democracia”. Novos Rumos. Ano 17. n. 37, 2002. p. 4-28.

RAGO, Margareth. Epistemologia feminista, gênero e história. Masculino, feminino, plural. Florianópolis, Ed. Mulheres, 1998, pp. 25-37.

SANTOS, Elisabete; NÓBREGA, Lígia.. Ensaio sobre o feminismo marxista socialista. Revista de humanidades, v. 05, n. 11, jul./set, 2004. Disponível em: http://www.cerescaico.ufrn.br/mneme. Acesso em jul. de 2018.

\title{
Outras epistemologias para os estudos de gênero: feminismos, interseccionalidade e divisão sexual do trabalho em debate a partir da América Latina
}

\section{Resumo \\ Desde a sua primeira onda, o movimento feminista surge como proposta para combater as desigualdades entre homens e mulheres, objetivando desconstruir a lógica masculina dominante. No entanto, o feminismo tradicional hegemônico, estruturado a partir das experiências das mulheres brancas e burguesas, conta com características universalizantes e totalizadoras, que acabam por desconsiderar outras mulheres. Nesse sentido, o feminismo decolonial surge com a proposta de revisitar os conceitos modernos ligados ao feminismo hegemônico, ao considerar a interseccionalidade. A interseccionalidade é marco fundamental para compreender as diversas posições que as mulheres ocupam na sociedade e dar visibilidade a grupos que até então não eram considerados no "ser mulher". A interseccionalidade traz como contribuição a consideração de que a divisão sexual de trabalho é também racial e de classe. Ademais, o conceito propõe para as ciências sociais uma análise sobre as diferentes formas de opressão e formas em que a "ferida colonial" se encarna nos corpos situados historicamente em processos particulares e locais. Considera-se importante, porém, tratar das críticas feitas ao conceito e apontar desafios teórico-metodológicos quanto à sua operacionalização. Em conclusão, o artigo aponta que existem interseccionalidades: as categorias de articulação variam de acordo com o grupo e seu contexto social, cultural e político. \\ Palavras-chave: Feminismo decolonial. Interseccionalidade. Divisão Sexual do Trabalho. Estudos de gênero. \\ Other epistemologies for gender studies: feminisms, intersectionality and the sexual division of labour under debate from Latin America}

\begin{abstract}
Since its first wave, the feminist movement emerges as a proposal to combat inequalities between men and women, aiming to deconstruct the dominant masculine logic. However, traditional hegemonic feminism, based on the experience of white and bourgeois women, has universalizing and totalizing characteristics that end up disregarding other women. In this context, decolonial feminism emerges as a proposal to review modern concepts connected to traditional hegemonic feminism - thought for a bourgeois white woman - highlighting the concept of intersectionality. Intersectionality is a fundamental point to understand the various positions that women occupy in society, giving visibility to groups that, until now, were not considered in the imaginary of "being woman". Moreover, intersectionality brings as contribution the fact that sexual division of labor is also racial and based in class. In addition, the concept proposes to social sciences an analysis of the different forms of oppression and ways in which the "colonial wound" is embodied in corps historically situated in particular and local processes.
\end{abstract}


Nevertheless, it is considered important to discuss the criticisms made to the concept and to point out theoretical-methodological challenges regarding its operationalization. As a conclusion, the article elucidates that what exists is, indeed, intersectionalities, that is, categories of articulation varying according to the group and its social, cultural and political context.

Key-words: Decolonial feminism. Intersectionality. Sexual division of labor. Gender studies.

\title{
Otras epistemologías para los estudios de genero: feminismos, interseccionalidad y división sexual del trabajo en el debate desde América Latina
}

\begin{abstract}
Resumen
Desde su primera ola, el movimiento feminista surge como una propuesta para combatir las desigualdades entre hombres y mujeres, con el objetivo de deconstruir la lógica masculina dominante. No obstante, el feminismo tradicional hegemónico, estructurado a partir de las experiencias de las mujeres blancas y burguesas, cuenta con características universalizantes y totalizadoras, que acaban por desconsiderar a otras mujeres. En ese contexto, el feminismo decolonial surge con la propuesta de revisar los conceptos modernos ligados al feminismo hegemónico tradicional, pensado para la mujer blanca burguesa, al considerar la interseccionalidad. La interseccionalidad es un marco fundamental para comprender las diversas posiciones que las mujeres ocupan en la sociedad y dar visibilidad a grupos que hasta entonces no eran considerados en el "ser mujer". La interseccionalidad trae como aporte la consideración de que la división sexual de trabajo es también racial y de clase. Además, el concepto propone para las ciencias sociales un análisis sobre las diferentes formas de opresión y formas en que la "herida colonial" se encarna en los cuerpos situados históricamente en procesos particulares y locales. Sin embargo, se considera importante tratar las críticas hechas al concepto y apuntar desafíos teóricometodológicos en cuanto a su operacionalización. En conclusión, el artículo apunta que existen interseccionalidades: las categorías de articulación varían de acuerdo con el grupo y su contexto social, cultural y político.

Palabras clave: Feminismo decolonial. Interseccionalidad. División Sexual del Trabajo. Estudios de género.
\end{abstract}

